\section{Chlorine in the stratosphere}

SIR - We have investigated the stable chlorine-isotope composition of several anthropogenic chlorinated organic compounds to test if the compositions of this isotope can be used to quantify the flux of stratospheric inorganic chlorine derived from the decomposition of these compounds. Chlorine has two stable isotopes with an atomic abundance ratio ${ }^{35} \mathrm{Cl}:{ }^{37} \mathrm{Cl}$ of $75.53: 24.47$ (ref. 1). Chlorine isotope compositions are expressed as $\delta^{37} \mathrm{Cl}$ values in per mil, where

$$
\delta^{37} \mathrm{Cl}=\left[\frac{{ }^{37} \mathrm{Cl} /{ }^{35} \mathrm{Cl}_{\text {Sample }}}{{ }^{37} \mathrm{Cl} /{ }^{35} \mathrm{Cl}_{\text {Standard }}}-1\right] 1,000
$$

and ${ }^{37} \mathrm{Cl}^{35} \mathrm{Cl}_{\text {Standard }}$ is the $\mathrm{Cl}$ isotope ratio of standard mean ocean water chloride. The variation in $\delta^{37} \mathrm{Cl}$ values of most naturally occuring $\mathrm{Cl}$ compounds is known to be very small ${ }^{2,3}$, with all measured values between -2 and +2 per mil. More important, natural $\mathrm{Cl}$ sources available to the atmosphere all have values between -1 and +1 per mil. As large kinetic isotope fractionations of chlorine have been observed for processes used to make anthropogenic chlorinated compounds ${ }^{4,5}$, we expected that each anthropogenic chlorinated compound would have a distinguishable isotope composition.

Chlorine isotope compositions were measured on Freon-12, carbontetrachloride, trichloroethylene, 1,2-dichloroethane, methylchloride and Chlordane (octachloro-4,7-methanotetrahydro indane). Chlorine in these compounds was extracted as $\mathrm{LiCl}$ by heating them with lithium metal in a sealed quartz tube. The extracted chlorine was converted into methylchloride and analysed for the isotope composition as described in ref. 6 . The standard was prepared by precipitating seawater $\mathrm{Cl}$ as $\mathrm{AgCl}_{2}$, and converting it to methylchloride using the method in ref. 6 . Replicate analysis of seawater $\mathrm{Cl}$ yielded a value of $0 \pm 0.15$ $(1 \sigma)$ per mil for four samples. Several of the methylchloride gas samples analysed for $\mathrm{Cl}$ isotope composition were subjected to the whole extraction procedure again to evaluate possible $\mathrm{Cl}$ isotope fractionation during the procedure. The original and reprocessed samples yielded identical results.

The analytical results are listed in the table. Methylchloride has a $\delta^{37} \mathrm{Cl}$ value of -6.8 for the vapour and -6.0 for the liquid. All the other compounds analysed have $\mathrm{Cl}$ isotope compositions similar to the $\mathrm{Cl}$ from naturally occurring $\mathrm{Cl}$ bearing compounds. The depletion of methylchloride in ${ }^{37} \mathrm{Cl}$ clearly indicates preferential incorporation of the lighter chlorine isotope $\left({ }^{35} \mathrm{Cl}\right)$ into methylchloride molecules during synthesis under a

large excess of reactant chlorine. On the other hand, given that the kinetic isotope fractionation factor for chlorine $\left(k^{35} / k^{37}\right)$ during the synthesis of chlorinated compounds is as large as 1.011 (refs

\section{STABLE CHLORINE ISOTOPE RATIO IN MAN-MADE CHLORINATED COMPOUNDS}

\section{Compounds} $\delta^{37} \mathrm{Cl}$ (per mil)

Methylchloride (vapour) (liquid)

$-6.82 \pm 0.15(1)$

1,2-dichloroethane $1.07 \pm 0.15(1)$

Carbontetrachloride

$0.87 \pm 0.15(1)$

Freon-12

$1.09 \pm 0.15(2)$

Trichloroethylene

$2.61 \pm 0.15(2)$

Chlordane*

$0.19 \pm 0.15(2)$

*Octachloro-4,7-methanotetrahydroindane

Numbers in parentheses, number of analyses.

4,5 ), the results for all other compounds require that chlorine must be quantitatively converted into the products during the synthesis of these compounds by recycling of the unreacted chlorine during the manufacturing process.

These results could allow quantification of the contribution of chlorine from natural methylchloride to the stratospheric inorganic chlorine budget, if natu-

\section{Bayesian reasoning}

SIR - Edwards states ${ }^{l}$ that the bayesian claim "that all parametric uncertainty can be measured by probabilities will remain in doubt until compelling arguments are advanced and scientists' misgivings thus removed", and opines that "this is probably not possible", offering references dating back to 1854 . Actually, a definitive bayesian argument was published in 1946 by $\mathrm{Cox}^{2,3}$. Apparently the force of this has not been sufficiently appreciated. I shall try to translate the Cox argument into modern idiom, avoiding the technical terms which have failed to convince, and thus try to reduce any misgivings.

Nowadays, I do all my inference with my computer. Its memory has about a billion $\left(10^{9}\right)$ bits, giving $2^{\text {billion }}$ possible patterns. Usually, aided by relevant data, I wish to express my relative preferences for these different patterns.

If I prefer pattern $P$ to pattern $Q$, and in turn prefer $Q$ to $R$, then I implicitly prefer $P$ to $R$. This transitivity (axiom 0 ) enables me to express my preferences as real numbers $\operatorname{pref}(P), \operatorname{pref}(Q)$,.

Though somewhat arbitrary, these are consistently ordered.

The simplest problem has just one bit $A$, and $2^{1}=2$ patterns, ' $A$ ' and 'not $A$ '. ral methylchloride is also depleted in ${ }^{37} \mathrm{Cl}$. Methylchloride is the most abundant naturally occurring chlorinated organic compound in the atmosphere; as it has a relatively long residence time there of about 2 years, it is recognized as one of the most important sources of natural chlorine into the stratosphere ${ }^{7}$. Obtaining the chlorine isotope composition of natural methylchloride in the atmosphere may be difficult because its very low volume mixing ratio, as low as 600 parts per $10^{12}(\mathrm{v} / \mathrm{v})$, in the atmosphere and sample size requirements for the analysis do not allow measurements with a gas source mass spectrometer. It should be possible, however, to perform the analyses on a thermal ionization or on an isotope-ratio monitoring ${ }^{8}$ mass spectrometer.

NORIYUKI TANAKA DANNY M. RYE

Department of Geology \& Geophysics. Yale University, Box 6666,

New Haven, Connecticut 06511, USA

1. Boyd, A. W., Brown, F. \& Lounsbury, M. Can. J. Phys. 33 35 (1955)

2. Hoering, T. C. \& Parker P. L. Geochim, cosmochim. Acta 23, 186-199 (1961)

Kaufmann, R. S., Long, A., Bentley, H. \& Davis, S Nature 309, 338-340 (1984)

Hill, J. W. \& Fry, A. J. Am. chem. Soc. 84, 2763 2769 (1962).

5. Turnquist, C. R., Taylor, J. W., Grimsrud, E. P. \& Williams, R. C. J. Am. chem. Soc. 95, 4133-4138 (1973).

6. Taylor, J. W. \& Grimsrud, E. P. Analyt. Chem. 41 805-810 (1969).

Cicerone, R. Rev. geophys. Space Phys. 19, 123 (1981) 8. Mathews, D. E. \& Hayes, J. M. Analyt. Chem. 50 1465-1473 (1978)

Insofar as I favour ' $A$ ', then I correspondingly disfavour 'not $A$ ', and vice versa. Hence I have a function $f$ of my numerical preferences such that

$$
\text { pref }(\text { not } X)=f(\operatorname{pref}(X))(\text { axiom 1) }
$$

The next simplest problem has two bits, $A$ and $B$, and $2^{2}=4$ patterns. To determine my preference for, say, $(A, B)$ with both $A$ and $B$ ON, I simplify. I inspect $A$ first, ignoring $B$, and assign my pref $(A)$. If $A$ is OFF, $B$ is irrelevant. If $A$ is $\mathrm{ON}$, then my conditional preference $\operatorname{pref}(B$ given $A)$ for $B$ lets me complete my joint preference for $(A, B)$. Hence I have another function $F$ such that

$\operatorname{pref}(A, B)=$
$F(\operatorname{pref}(A), \operatorname{pref}(B$ given $A))$

(axiom 2)

and this must be the same as $\operatorname{pref}(B, A)$.

The next problem has three bits, say $A, B, C$. In order to determine my preference for, say, $(A, B, C)$, I can read the constituent bits in any order, giving six procedures which must all give the same pref $(A, B, C)$. Cox proved the following. He can always stretch my preferences into revised numerical values for which his functions are $f\left(x^{\prime}\right)=$ $1-x^{\prime}$ and $F\left(x^{\prime}, y^{\prime}\right)=x^{\prime} y^{\prime}$. In other words, he has an absolute scale prob $(X)$ 